\title{
On the role of the GRACE mission in the joint assimilation of altimetric and TAO data in a tropical Pacific Ocean model
}

\author{
F. Castruccio, ${ }^{1}$ J. Verron, ${ }^{1}$ L. Gourdeau, ${ }^{2}$ J. M. Brankart, ${ }^{1}$ and P. Brasseur ${ }^{1}$ \\ Received 23 January 2006; revised 31 May 2006; accepted 6 June 2006; published 26 July 2006.
}

[1] Recent advances in our knowledge of the earth geoid have made it possible to exploit absolute sea surface height measurements in realistic numerical modelling studies of the ocean. This letter provides evidence of the benefit of the GRACE referenced mean dynamic topography (MDT) for the simulation of the tropical Pacific ocean through the joint assimilation of altimetric data and of vertical temperature profiles from the TAO/TRITON array. Results are considered in relation to those obtained using a classical model MDT, based on the model itself, and are validated against independent XBT data. The use of the GRACE MDT leads to significantly improved results with respect to these independent data. If the compatibility between the altimetric sea surface height and the TAO/TRITON temperature improves the model simulation, some limitations exist, especially in the Warm Pool where a part of the sea surface height signature is associated to a salinity signal. Citation: Castruccio, F., J. Verron, L. Gourdeau, J. M. Brankart, and P. Brasseur (2006), On the role of the GRACE mission in the joint assimilation of altimetric and TAO data in a tropical Pacific Ocean model, Geophys. Res. Lett., 33, L14616, doi:10.1029/2006GL025823.

\section{Introduction}

[2] Altimetry is today a major field of oceanographic developments, in particular for ocean monitoring and prediction through data assimilation into ocean models. However, only the residual component (the Sea Level Anomaly or SLA) of the altimetric measured signal (the Sea Surface Height or $\mathrm{SSH}$ ) can reliably be used. The mean altimetric reference, the so called Mean Dynamic Topography (MDT) [e.g., Birol et al., 2005], is contaminated by large geoid errors (especially with high order harmonics). The dynamic topography which is the relevant oceanic quantity, and results from the addition of the SLA and the MDT, was only accessible through the use of a synthetic MDT evaluated by indirect and often approximate approaches. The gravimetric satellite missions such as CHAMP (2000), GRACE (2002) and GOCE (2007) are changing this perspective by providing a more accurate geoid reference and the possibility of using the absolute altimetric signal [Gourdeau et al., 2003; Birol et al., 2005].

[3] The objective of this work is to investigate the assimilation of this absolute altimetric signal and to show

\footnotetext{
${ }^{1}$ Laboratoire des Ecoulements Géophysiques et Industriels, UMR 5519, CNRS, Institut National Polytechnique de Grenoble, Université Joseph Fourier, Grenoble, France.

${ }^{2}$ UMR 065, Institut de Recherche pour le Développement, Nouméa, New Caledonia.
}

Copyright 2006 by the American Geophysical Union. 0094-8276/06/2006GL025823 how this can impact the assimilation of multiple source data. The investigation is performed with a model of the tropical Pacific ocean where an easily accessible and rather synoptical set of in-situ data is available, thanks to the TAO/ TRITON moorings, to complement the altimetric observations. The Singular Evolutive Extended Kalman (SEEK) filter is used to jointly assimilate the TOPEX/Poseidon and ERS SSH referenced to the GRACE geoid, and the TAO/ TRITON temperature profiles. A set of two experiments is conducted: the first assumes a pre-GRACE situation using an artificial MDT from the model itself (as has been often done until now), while the second uses the new capability provided by a fully measured MDT computed with the GRACE geoid (hereafter denoted shortly as the "GRACE MDT").

[4] The following section, Section 2, describes the model and the data sets. Section 3 focuses on the assimilation system while Section 4 discusses the results of the data assimilation experiments and evaluates them in particular against independent XBTs. Section 5 draws some conclusions.

\section{Model and Data Sets}

\subsection{The Numerical Model}

[5] The OPA OGCM (www.lodyc.jussieu.fr/opa) is based on the standard ocean primitive equations and uses a free surface formulation. The configuration is the so-called ORCA2 global configuration: the extratropical $2^{\circ} \times 2^{\circ}$ mesh has a meridional grid spacing refinement down to $0.5^{\circ}$ in the tropics to improve the equatorial dynamics. Along the vertical, there are $31 \mathrm{z}$-levels. This model has been used extensively for tropical dynamic studies and validated accordingly [e.g., Lengaigne et al., 2003].

[6] In the tropics, ocean dynamics are critically determined by wind stresses. For this reason, the ERS scatterometer wind stresses complemented by TAO derived stresses, which together tend to produce more realistic thermocline and zonal currents, are used as proposed by Menkes et al. [1998]. Regarding heat and fresh water flux, the 1957-2002 ERA40 ECMWF reanalysis is used. A local feedback term is added to account for the coupling between the surface ocean heat flux and the sea surface temperature (SST) with a feedback coefficient of $-40 \mathrm{Wm}^{-2} \mathrm{~K}^{-1}$. A restoring term is also applied on sea surface salinity (SSS) to avoid unrealistic drift. The model is initialized with Levitus climatology. It is spun up over a period of 4 years and then the interannual experiment starts in January 1992. The year 1993 is chosen for the present analysis.

\subsection{The Observation Data}

\subsubsection{TOPEX/Poseidon and ERS}

[7] The altimetric observations used for assimilation consist of along-track SLA from the TOPEX/Poseidon 


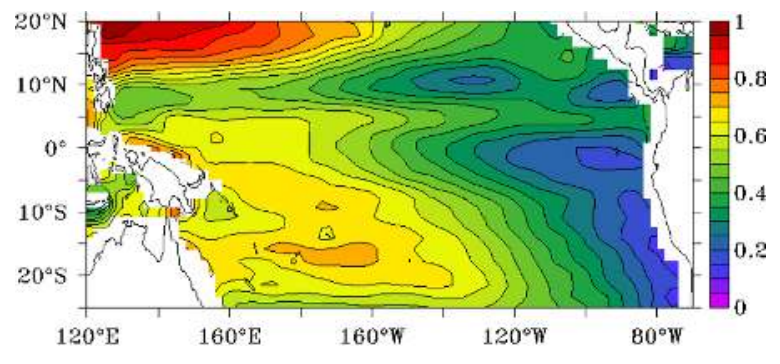

Figure 1. GRACE MDT (in meter).

and ERS satellite altimeters. The data are processed by the AVISO Altimetry group (www.jason.oceanobs.com).

\subsubsection{GRACE}

[8] The so called GRACE MDT (Figure 1) used in this study (EXP2) is the difference between a Mean Sea Surface Height (MSSH) and a geoid. The MSSH corresponds to a 7-year mean (1993-1999) based on the TOPEX/Poseidon, ERS1-2 and GEOSAT follow-on altimetric data (the same as the one used for the SLA computation). The geoid is deduced from the EIGEN-GRACE02S Earth gravity field from GFZ-Potsdam, developed to degree 60 and based on 110 days of GRACE data. This GRACE MDT solution reasonably fits the real tropical Pacific MDT. This is illustrated, for example, by the maps in Figure 2 which shows the difference between the 0/500 dbar TAO dynamic height and the GRACE MDT for the 1993-2001 period (Figure 2b). The TAO dynamic height is evaluated using salinity estimated from a local T-S relation computed from climatological data. The order of magnitude of the error due to the 500-dbar reference level and the inaccurate estimation of salinity is about $2-3 \mathrm{~cm}$, growing up to $6 \mathrm{~cm}$ in the Warm Pool. The free model MDT is also shown on Figure 2a and compare poorly with TAO. The overall RMS difference (RMSD) is $4.0 \mathrm{~cm}$ for the free model MDT and only $1.9 \mathrm{~cm}$ for the GRACE MDT. Most of the GRACE remaining differences are concentrated in the western part of the Equatorial Pacific ocean.

\subsubsection{TAO}

[9] Altimetric data and in-situ temperature profiles are jointly assimilated into the model. Profiles from the TAO/ TRITON array are used in this study (www.pmel.noaa.gov/ tao). The TAO/TRITON array consists of about 70 moorings between $8^{\circ} \mathrm{N}-8^{\circ} \mathrm{S}, 137^{\circ} \mathrm{E}-95^{\circ} \mathrm{W}$, providing highquality temperature measurements in the upper $500 \mathrm{~m}$.

\subsubsection{XBT}

[10] In order to validate the thermal structure of our simulations, independent XBT profiles collected in the Tropical Pacific during the year 1993 are used. The profiles come from the CORIOLIS database (www.coriolis.eu.org). We used around 17500 temperature profiles from the surface down to 700-meter depth over the year 1993.

\section{Data Assimilation Scheme}

\subsection{Assimilation Scheme}

[11] The assimilation scheme is based on the Singular Evolutive Extended Kalman (SEEK) filter introduced by Pham et al. [1998]. This sequential method has already been used and assessed in the tropical Pacific [e.g., Verron et al., 1999]. In this study the forecast error covariance matrix is kept constant in time as in work by Gourdeau et al. [2000], and the correction is applied on the full 3D model state vector (temperature, salinity, meridional and zonal velocity). Even though our model is global, data assimilation is only applied in the tropical Pacific domain defined-following Durand et al. [2003] - between $25^{\circ} \mathrm{S}$ and $20^{\circ} \mathrm{N}$ in latitude and from $120^{\circ} \mathrm{E}$ to the American coast in longitude. Buffer zones are used to smoothly connect the assimilated domain to extra tropical zones. In addition to the regular SEEK filter procedure an Incremental Analysis Update (IAU) algorithm was implemented to smooth out the time discontinuity of the solution resulting from intermittent corrections of the model state [see Ourmières et al., 2006].

\subsection{Parametrization of the Error Covariances}

[12] The parametrization of the error covariances is a primary factor in the efficiency of the assimilation process. An ensemble procedure is used to identify the appropriate reduced space for $\mathbf{P}^{f}$. It is first assumed that a model simulation with a strong relaxation toward climatological fields provides a good approximation of the mean true ocean. Then by using this reference run to reinitialize the free run every 5 days during one year, an ensemble of differences between this reference simulation and the free model 5-day forecasts without nudging is generated. This ensemble of 73 members represents the 5 -day forecast error between the model and the reference trajectory. The covariance of this ensemble turns out to be an appropriate estimate of the model error covariance, needed to parameterize the SEEK filter. The rank of this matrix is reduced using a limited number (30) of threedimensional, multivariate empirical orthogonal functions (EOFs) describing the dominant modes of the ensemble covariance.

[13] Regarding the parameterization of the observation errors covariance, a diagonal matrix is used with respec-

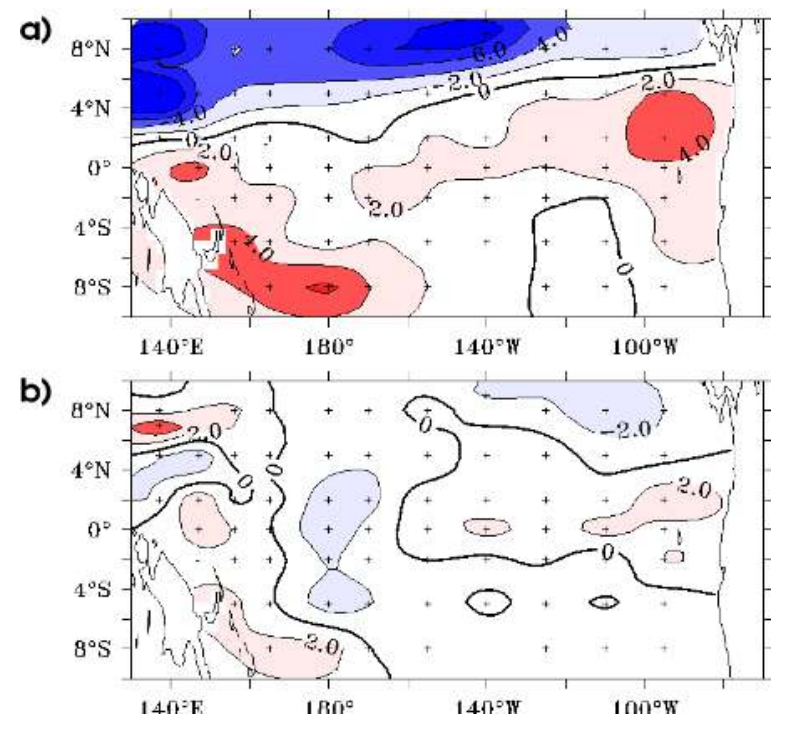

Figure 2. Difference for the 1993-2001 period between the mean 0/500 dbar TAO dynamic height and the model MDT (a) and the GRACE MDT (b). Contour interval is $2 \mathrm{~cm}$. TAO moorings are located at crosses. 

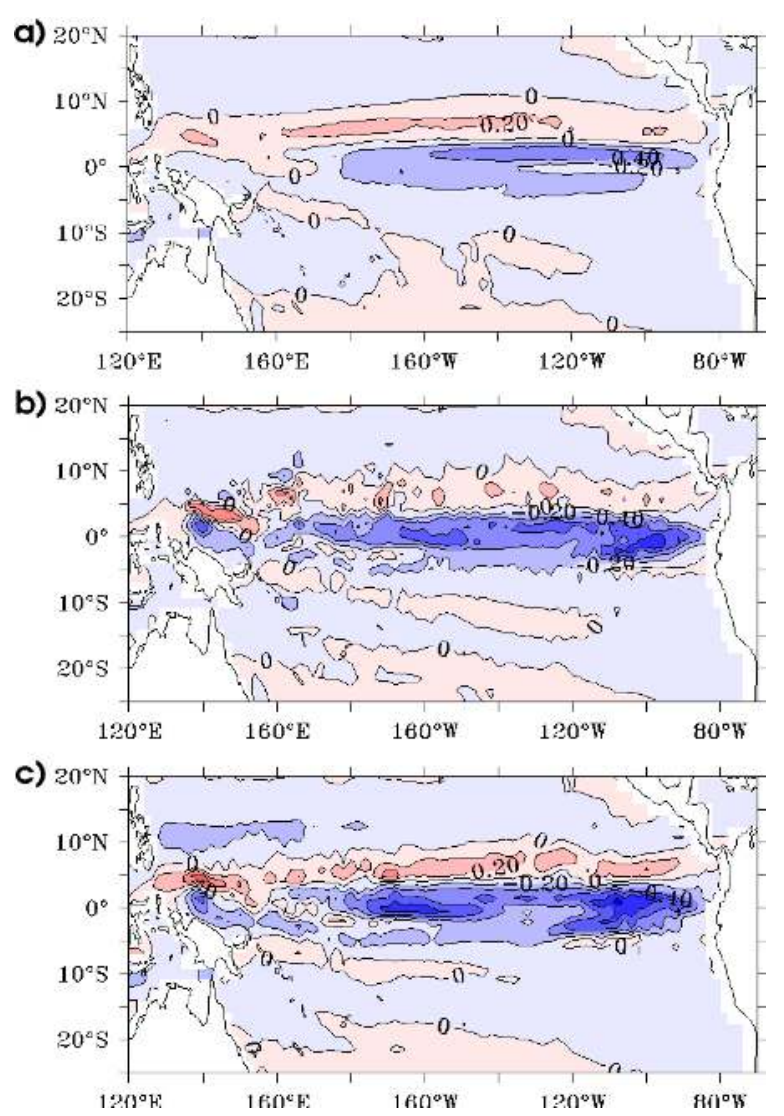

Figure 3. Mean zonal velocity for year 1993 at $25 \mathrm{~m}$ depth for the free run (a), for EXP1 (b) and for EXP2 (c). Contour interval is $0.2 \mathrm{~ms}^{-1}$.

tively $3 \mathrm{~cm}$ and $0.1^{\circ} \mathrm{C}$ standard deviation for altimetry and temperature data.

\section{Data Assimilation Experiment}

[14] The data assimilation system described above is used to perform two assimilation experiments over the year 1993. As stated earlier, the two simulations only differ in the choice of the MDT: EXP1 uses altimetric data referenced to the model MDT, -which has a certain bias with regard to a TAO derived MDT (Figure 2a)-, while EXP2 uses altimetric data referenced to the GRACE MDT, -which has a less pronounced bias with regard to TAO (Figure 2b). Parent et al. [2003], in particular, have shown that performing a joint assimilation of SLA data with in-situ data may reach a deadlock due to the different reference mean states of the two types of data. It is therefore expected here that the better data mean state compatibility present in EXP2 will contribute to provide a more efficient assimilation, making a better use of data complementarity.

[15] A preliminary examination of the ability of the system to simulate the tropical Pacific circulation is illustrated in Figure 3 showing the mean zonal velocity fields at $25 \mathrm{~m}$ depth. The alternate bands of eastward- and westwardflowing currents characterizing the Tropical Pacific ocean circulation are present in the 3 runs. The free run currents are too weak. In Figure $3 b$ the EXP1 mean zonal currents are uncharacteristically noisy for an annual mean, especially along $8^{\circ} \mathrm{N}$, where the model produces the largest errors with regard to the TAO derived MDT, and where the incompatibility of the data sets is the most striking, as it is illustrated by the noisy small patterns. The EXP2 mean zonal currents are the closest to the drifter derived climatology proposed by P. Niiler [see Lengaigne et al., 2003], thanks to the GRACE MDT which is known to feature all major geostrophic currents [Tapley et al., 2003].

[16] Among the many diagnostics that could be shown, attention is drawn here to the predicted MDTs (with reference to GRACE) and to the vertical temperature profiles (compared to independent XBTs).

\subsection{MDTs}

[17] The maps in Figure 4 show the difference between the simulated MDTs for the year 1993 and the observed MDT deduced from GRACE. The free-run RMSD (Figure $4 \mathrm{a}$ ) is $4.4 \mathrm{~cm}$ over the whole domain. In EXP1 (Figure 4b), the RMSD increases to $5.7 \mathrm{~cm}$. The solution is a long way from the observations, even further than the free run, especially along $8^{\circ} \mathrm{N}$. Note that, assimilating the TAO temperature profiles only (experiment not shown) leads to a reduction in the RMSD, which is another evidence of the compatibility between the SSH referenced to GRACE geoid and in-situ TAO data. The EXP1 increase in the RMSD shows that the use of different types of observations can indeed be conflictual as noted by Parent et al. [2003].

[18] The assimilation system manages to drive the solution close to the observations in EXP2 (Figure 4c). The
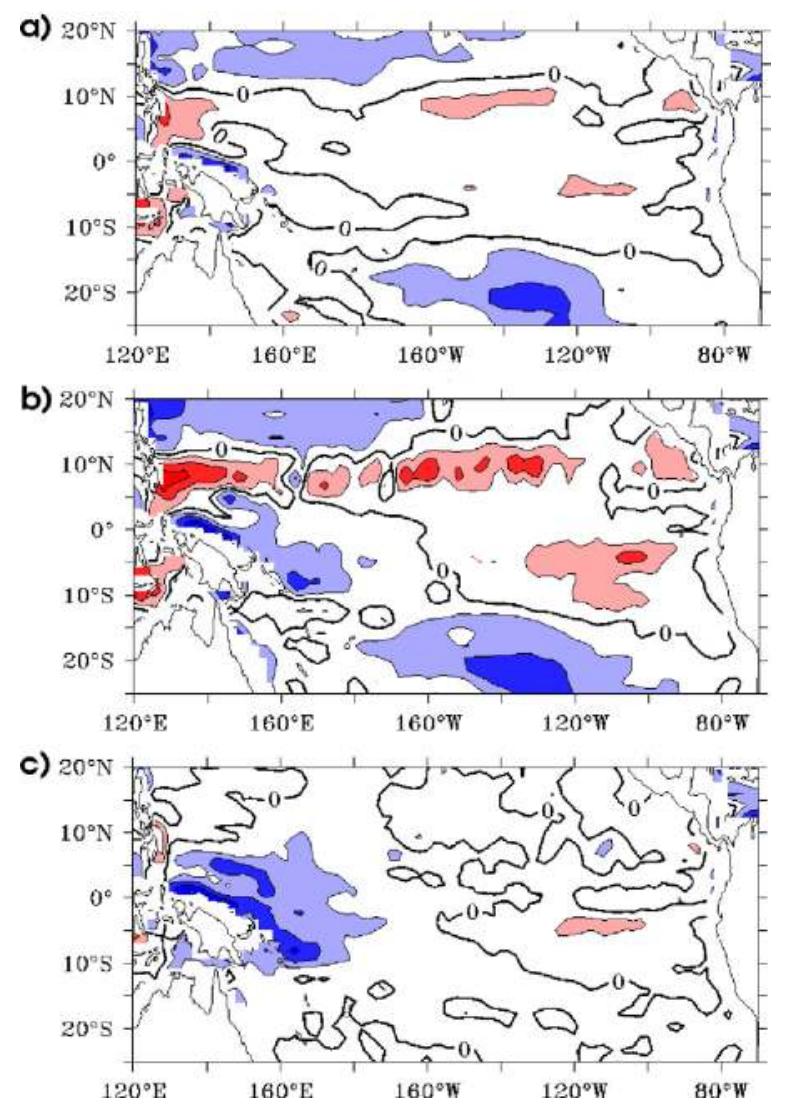

Figure 4. Difference maps between the simulated MDT for year 1993 and the satellite observed MDT for the free run (a), for EXP1 (b) and for EXP2 (c). Contour interval is $5 \mathrm{~cm}$. 
RMSD with respect to the observed MDT is $3.6 \mathrm{~cm}$. The differences map reveals a narrow region of remaining large errors in the $10^{\circ} \mathrm{S}$ and $10^{\circ} \mathrm{N}$ strip west of the date line. The RMSD in this region increases up to $6.9 \mathrm{~cm}$. Interestingly, the large errors area squares with the region of significant remaining errors with respect to the TAO dynamic height (see Figure 2b). Several hypotheses can be advanced to explain the concentration of errors within the Warm Pool. In particular, salinity variations insufficiently controlled by data assimilation, may significantly affect the SSH signal in this region [Maes, 1998]. This can also account for the differences observed in Figure $2 b$ in the same region. This suggests that both salinity and temperature data should be considered for joint assimilation with altimetric data.

[19] The error patterns in Figure 4c led us to re-evaluate the EXP2 RMSD, excluding the $10^{\circ} \mathrm{S}$ and $10^{\circ} \mathrm{N}$ strip west of $180^{\circ} \mathrm{E}$. The RMSD is then as low as $2.9 \mathrm{~cm}$, thus confirming that a specific issue does exist in this sub-region.

\subsection{Validation Using Independent XBT Profiles}

[20] To further assess the results, we evaluated the experiments using independent XBT data. RMSD between the XBTs profiles over the whole domain and their model equivalent interpolated in space and time at profile location were computed and the results are shown in Figure 5. EXP1 is barely better than the free run, whereas EXP2 shows significant improvements for depths ranging from $40 \mathrm{~m}$ down to $250 \mathrm{~m}$.

[21] Table 1 summarizes the results. It presents RMSD with respect to the assimilated observations ( $\mathrm{SSH}, \mathrm{TAO}$ ) and with respect to independent observation (XBT), the later being undoubtedly most meaningful to evaluate the performance of our assimilation system. When considering the SSH a significant RMSD decrease is seen from $7.6 \mathrm{~cm}$ RMS for the free run to 5.8 for EXP2, that is more than $40 \%$ error variance decrease. With respect to TAO data, the decrease in the error is even larger (more than $60 \%$ in variance). As far as the assimilation of TAO data is concerned, the presence of the GRACE MDT slightly

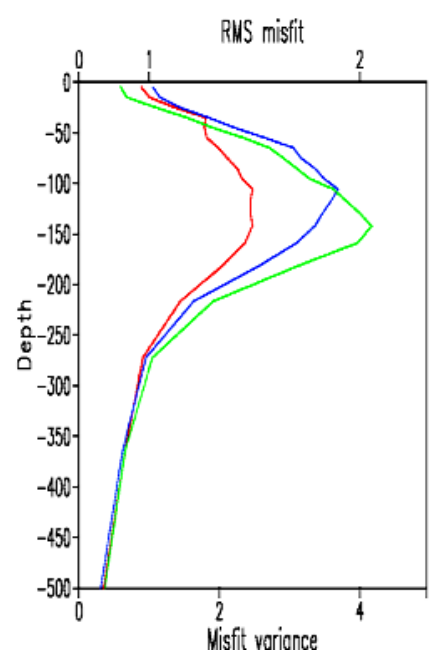

Figure 5. Temperature RMSD with respect to independent XBT data for the $25^{\circ} \mathrm{S}$ and $20^{\circ} \mathrm{N}$ strip for year 1993 for the free run (green), for EXP1 (blue) and for EXP2 (red).
Table 1. Standard Deviation and Percentage Error Variance Reduction (in Parentheses) of the RMS Misfit With Respect to the SSH Referenced to GRACE MDT and the TAO and XBT Temperature Profiles ${ }^{\mathrm{a}}$

\begin{tabular}{lccc}
\hline & SSH, cm & TAO, deg & XBT, deg \\
\hline Free & 7.62 & 1.31 & 1.52 \\
EXP1 & $7.18(-11 \%)$ & $0.72(-70 \%)$ & $1.51(-0.02 \%)$ \\
EXP2 & $5.84(-41 \%)$ & $0.82(-61 \%)$ & $1.31(-26 \%)$ \\
EXP2* & $5.62(-45 \%)$ & $0.79(-63 \%)$ & $1.21(-38 \%)$ \\
\hline
\end{tabular}

${ }^{\mathrm{a}} \mathrm{EXP} 2 *$ excludes the Western Equatorial region (see text).

degrades the performances from EXP1 to EXP2, which is a sign that data incompatibilities remains. Finally, and most importantly, with respect to XBT data, RMSD is $1.52^{\circ} \mathrm{C}$ for the free run, $1.51^{\circ} \mathrm{C}$ for EXP1 and $1.3^{\circ} \mathrm{C}$ for EXP2. RMSD is as low as $1.21^{\circ} \mathrm{C}$ when the West Equatorial Pacific ocean is excluded. This is a strong argument supporting the importance of GRACE data to jointly assimilate TAO and SSH observations.

\section{Conclusion}

[22] The objective of this study was to assess how the use of a GRACE geoid could improve the modeling of tropical Pacific dynamics through data assimilation of altimetric and in-situ data. The study was motivated by the fact that defining the MDT reference is a recurrent problem in altimetric data assimilation studies and that ongoing and future satellite missions dedicated to the improvement of the earth geoid are likely to change this situation. The benefits brought by the use of a GRACE MDT in the assimilation system are clear. The first results are positive, especially in terms of improved compatibility between in-situ and satellite data observations. This emphasizes that the observation data sets have to be coherent in order to be efficiently assimilated into an OGCM. Nevertheless, we identified a region (corresponding approximately to the Warm Pool) where both the observed MDT and the assimilated solution have large errors, thus suggesting that salinity effects should be considered more carefully and that the use of in-situ salinity data may be required. The use of an absolute dynamic topography opens the way for the development of efficient assimilation systems based on multiple data sets (using altimetry and various in-situ data). Further improvements in the knowledge of the MDT itself might result from converging studies on assimilated data resolution and accuracy, both from space and in situ, on modeling and on assimilation techniques, within the context of operational oceanography systems [Dobricic, 2005].

[23] Acknowledgments. This work was supported by the Centre National d'Etude Spaciales (CNES), the Centre National de Recherche Scientifique (CNRS) and the Groupe Mission Mercator Coriolis (GMMC). The research took place as part of the EU funded MERSEA project. The calculations were conducted with the support of IDRIS/CNRS.

\section{References}

Birol, F., J. M. Brankart, J. M. Lemoine, P. Brasseur, and J. Verron (2005), Assimilation of satellite altimetry referenced to the new GRACE geoid estimate, Geophys. Res. Lett., 32, L06601, doi:10.1029/2004GL021329.

Dobricic, S. (2005), New mean dynamic topography of the Mediterranean calculated from assimilation system diagnostics, Geophys. Res. Lett., 32, L11606, doi:10.1029/2005GL022518. 
Durand, F., L. Gourdeau, T. Delcroix, and J. Verron (2003), Can we improve the representation of modeled ocean mixed layer by assimilating surface-only satellite-derived data? A case study for the tropical Pacific during the 1997-1998 El Niño, J. Geophys. Res., 108(C6), 3200 doi:10.1029/2002JC001603.

Gourdeau, L., J. Verron, T. Delcroix, A. Busalacchi, and R. Murtugudde (2000), Assimilation of TOPEX/Poseidon altimetric data in a primitive equation model of the tropical Pacific Ocean during the 1992-1996 El Niño-Southern Oscillation period, J. Geophys. Res., 105(C4), $8473-8488$.

Gourdeau, L., J. M. Lemoine, M. H. Rio, and F. Hernandez (2003), Estimating mean dynamic topography in the tropical Pacific Ocean from gravity and altimetry satellites, Geophys. Res. Lett., 30(20), 2062 , doi:10.1029/2003GL018200.

Lengaigne, M., G. Madec, C. Menkes, and G. Alory (2003), Impact of isopycnal mixing on the tropical ocean circulation, J. Geophys. Res., 108(C11), 3345, doi:10.1029/2002JC001704.

Maes, C. (1998), Estimating the influence of salinity on sea level anomaly in the ocean, Geophys. Res. Lett., 25, 3551-3554.

Menkes, C., J. P. Boulanger, A. Busalacchi, J. Vialard, P. Delecluse, M. J. McPhaden, E. Hackert, and N. Grima (1998), Impact of TAO vs. ERS wind stresses onto simulations of the tropical Pacific Ocean during the 1993-1998 period by the OPA OGCM, in Climate Impact of Scale Interaction for the Tropical Ocean-Atmosphere System, Euroclivar Workshop Rep. 13, pp. 46-48, Eur. Cent. for Medium-Range Weather Forecasts, Reading, U. K.
Ourmières, Y., J. M. Brankart, L. Berline, P. Brasseur, and J. Verron (2006), Incremental analysis update implementation into a sequential ocean data assimilation system, J. Atmos. Oceanic Technol., in press.

Parent, L., C. E. Testut, J. M. Brankart, J. Verron, P. Brasseur, and L. Gourdeau (2003), Comparative assimilation of TOPEX/Poseidon and ERS altimeter data and of TAO temperature data in the tropical Pacific Ocean during 1994-1998, and the mean sea-surface height issue, J. Mar. Syst., 40-41, 381-401.

Pham, D., J. Verron, and M. Roubaud (1998), A singular evolutive extended Kalman filter for data assimilation in oceanography, J. Mar. Syst., $16,323-340$.

Tapley, B. D., D. P. Chambers, S. Bettadpur, and J. C. Ries (2003), Large scale ocean circulation from the GRACE GGM01 Geoid, Geophys. Res Lett., 30(22), 2163, doi:10.1029/2003GL018622.

Verron, J., L. Gourdeau, D. Pham, R. Murtugudde, and A. Busalacchi (1999), An extended Kalman filter to assimilate satellite altimeter data into a nonlinear model of the tropical Pacific: Method and validation, J. Geophys. Res., 104, 5441-5458.

J. M. Brankart, P. Brasseur, F. Castruccio, and J. Verron, LEGI, UMR 5519, CNRS-INPG-UJF, BP 53X, F-38041 Grenoble Cedex 9, France. (verron@hmg.inpg.fr)

L. Gourdeau, UMR 065, IRD, BP A5, 98848 Nouméa Cedex, New Caledonia. 